\title{
RURAL LAND-USE TRENDS IN THE CONTERMINOUS UNITED STATES, 1950-2000
}

\author{
Daniel G. Brown,,${ }^{1,5}$ Kenneth M. Johnson, ${ }^{2}$ Thomas R. Loveland, ${ }^{3}$ And David M. Theobald ${ }^{4}$ \\ ${ }^{1}$ School of Natural Resources and Environment, University of Michigan, Ann Arbor, Michigan 48109-1041 USA \\ ${ }^{2}$ Department of Sociology, Loyola University, Chicago, Illinois 60626 USA \\ ${ }^{3}$ USGS, Eros Data Center, Sioux Falls, South Dakota 57198 USA \\ ${ }^{4}$ Natural Resources Ecology Lab, Colorado State University, Fort Collins, Colorado 80523-1499 USA
}

\begin{abstract}
In order to understand the magnitude, direction, and geographic distribution of land-use changes, we evaluated land-use trends in U.S. counties during the latter half of the 20th century. Our paper synthesizes the dominant spatial and temporal trends in population, agriculture, and urbanized land uses, using a variety of data sources and an ecoregion classification as a frame of reference. A combination of increasing attractiveness of nonmetropolitan areas in the period 1970-2000, decreasing household size, and decreasing density of settlement has resulted in important trends in the patterns of developed land. By 2000, the area of low-density, exurban development beyond the urban fringe occupied nearly 15 times the area of higher density urbanized development. Efficiency gains, mechanization, and agglomeration of agricultural concerns has resulted in data that show cropland area to be stable throughout the Corn Belt and parts of the West between 1950 and 2000, but decreasing by about 22\% east of the Mississippi River. We use a regional case study of the Mid-Atlantic and Southeastern regions to focus in more detail on the land-cover changes resulting from these dynamics. Dominating were land-cover changes associated with the timber practices in the forested plains ecoregions and urbanization in the piedmont ecoregions. Appalachian ecoregions show the slowest rates of landcover change. The dominant trends of tremendous exurban growth, throughout the United States, and conversion and abandonment of agricultural lands, especially in the eastern United States, have important implications because they affect large areas of the country, the functioning of ecological systems, and the potential for restoration.
\end{abstract}

Key words: agriculture; demography; dispersed development; land-use change.

\section{INTRODUCTION}

The process of land-use change is a critical link between human activity and changes in the biosphere (Turner et al. 1995). Though land-use trends affect a variety of changes to ecological systems around the world, spatially explicit data on these trends is not always easy to acquire. The situation in the United States is somewhat better than elsewhere, but summaries of data on trends in land use across a variety of sectors are still rare. While the ecological causes and consequences of land-use changes are described elsewhere in this volume (Dale et al. 2005, Hansen et al. 2005, Huston 2005), this paper provides context by summarizing trends based on several recently created data set.

Much is already known about land-use trends in the United States. The interrelated histories of demograph-

Manuscript received 21 July 2003; revised 3 September 2004; accepted 8 November 2004; final version received 2 December 2004. Corresponding Editor: M. G. Turner. For reprints of this Invited Feature, see footnote 1, p. 1849.

5 E-mail: danbrown@umich.edu ic and agricultural changes were studied, for example, in the Land Use History of North America project (see especially Imhoff et al. 1998, Maizel et al. 1998). Other larger-scale data sets and analyses (e.g., Ramenkutty and Foley 1999, Dobson et al. 2000) provide support to global change analyses and have been used to drive global models but are not particularly useful for understanding the landscape and regional geographic patterns of change. The analyses of existing county-level data by Waisanen and Bliss (2002) and Theobald (2001), however, provide new opportunities to interpret these changes in ways that more clearly highlights their implications for ecological systems. In particular, the agricultural history can focus more explicitly on the history of specific types of agriculture (i.e., cropped vs. pasture) and the demographic history can focus more explicitly on the density of housing units, which more closely relates to landscape changes of interest to ecologists (Radeloff et al. 2000, Hammer et al. 2004). By examining these trends in tandem, we hope to present a useful summary of the potential land-use impacts on ecological systems in the United States. 
One way to examine human land use is to map distributions of human populations, as an indicator of human demand for various goods and services provided by ecological systems. The decennial U.S. Census of Population provides the most reliable and detailed source of this kind of information. The advantage of working with population and associated demographic data is that we can analyze both the population changes and their demographic components (e.g., natural increase or decrease and migration). Urbanization, however, is defined as the expansion of urban land uses, including commercial, industrial, and residential. Changes in population densities are often used as a surrogate for urbanization (Vesterby and Heimlich 1991, Fulton et al. 2001). Population data are tied to primary residence and thus underestimate development in rural areas, especially those affected by significant seasonal and recreational use. Furthermore, there are important land-use changes at or beyond the urban fringe, including conversion of land in agriculture and forest, which are not well represented in traditional definitions of urbanization. These changes, as affected by urbanization, need to be quantified because they affect large geographic areas and can have important cumulative effects on ecological systems. We make use of information in the U.S. Census about housing units, which represent a physical manifestation of urban settlement. Housing unit data also take into account the declines in household size that have resulted in landscape and ecosystem impacts that outstrip changes in population totals (Liu et al. 2003). We use these data to derive measures of urbanization. Though they do not include information on commercial or industrial land uses, data on the densities of housing units can be used as more precise indicators of urban land use and development at various degrees of intensity.

Agricultural land use has had important and widespread effects on ecological systems throughout the history of European settlement (Ramenkutty and Foley 1999). Original land settlement included widespread efforts to bring land under cultivation. However, agricultural land area in the United States declined during the 20th century (Vesterby and Krupa 1997). The decline can be attributed to both appropriation of agricultural land for other uses (i.e., urbanization) and abandonment of agriculture on poor quality land (Maizel et al. 1998). The patterns of change can be observed using data collected by U.S. Census of Agriculture, which reports information on the state of our nation's farms every five years (U.S. Department of Agriculture 1997). Because agriculture represents a large range of activities with varying degrees and types of ecological impact, we summarize the total amount of cropland, which distinguishes farmlands used for crops from those that are woodland, pastureland, or rangeland. Cropland is the most consistent indicator of land used for agricultural production available in the census re- cord (Waisanen and Bliss 2002) and represents the most intensively managed forms of agriculture. It should be noted, however, that cropland varies in its ecological impacts according to how and how intensively it is managed, e.g., through the use of irrigation, fertilizers, pesticides, and herbicides. While these variations are important determinants of the ecological effects of agricultural land use, we focus exclusively on the amount of land area in use for crops.

Though the land-use data presented here are probably the best available at the resolution of U.S. counties for longer-term national-level assessments, ecologists often need finer-grained information about land-use patterns and impacts. Further, local impacts of landuse change are often determined by changes in land cover, which refers to the biophysical state of land. Remote sensing is an important source of information about changes in land cover. Aerial photographs are available going back to the 1930s and civilian satellite images going back to the early 1970s. Obtaining and processing nationwide imagery at sufficient detail to identify land-cover types is exceedingly expensive (e.g., Lunetta et al. 1998, Vogelmann et al. 1998). The U.S. Geological Survey has undertaken to estimate land-cover change rates by processing and interpreting sampled satellite imagery within ecoregions across the entire United States (Loveland et al. 2002). To provide detail to the national level patterns presented here, we report on the first results from this work, which focus on ecoregions in the southeastern portion of the country.

The two primary objectives of the paper are to (1) summarize patterns of change in settlement and croplands in the United States between 1950 and 2000, resolved at the county level, and (2) present initial results from a more finely detailed investigation of landuse and cover change in parts of the East and South that relies on remote sensing data acquired between 1973 and 2000. Given that the finer resolution data cover only the period after 1973 , and that significant differences have been observed between the demographic trends in the period from 1950 to 1970 and those after 1970 (Johnson and Fuguitt 2000), we focus our discussion of national-level trends on these two periods. We seek to conceptually link summaries of land-use change more closely to cause and effect by subdividing the United States by (a) ecoregions and (b) county designations on a rural-urban gradient. Ecoregions define "regions of relative homogeneity in ecological systems or in relationships between organisms and their environments" (Omernik et al. 1987:123) and provide (1) a means to localize estimates of the rates and driving forces of change, and (2) a framework that can be extended globally. Because of the importance of urban systems in organizing human activities and the availability of county-level data for this study, we use metropolitan and nonmetropolitan county desig- 
nations to account for different land-use trends in rural vs. urban areas.

\section{Data And Methods}

\section{Counties and ecoregions}

All national-level data were compiled into a single county boundary file, representing boundaries from the USGS county boundary data set with a source scale of 1:2 000000 . We present county population and landuse data as a ratio of the land area in the county. The census calculates the land area for each block group, which is a subdivision of the more familiar census tract. This figure excludes permanent water bodies such as lakes, reservoirs, and large ponds. In rural areas, block groups can also include public lands. Because development and cropped agriculture are by-and-large precluded from occurring on public lands, the public land portions were removed from the block groups. In the 11 Western states, lands mapped as public by the states' gap analysis programs were used to erase the overlapping block groups. In the remaining 37 states (not including Alaska and Hawaii), lands mapped as public (except Indian Reservations) by the USGS National Atlas were used (available online). ${ }^{6}$ The total private land area for each county, resulting from adding up all block group areas, was used as the denominator when calculating all densities and ratios. The effect of using only private land areas is to increase density estimates where there are large public land holdings by decreasing the size of the denominator, i.e., the total land area available. We believe this is reasonable because estimates based on total, rather than private, land area underestimate the impact of settlement and agricultural activity on lands where they are practiced. The result, however, is estimates of density that apply only to the private lands. The influences of public land reserves on ecological systems are, therefore, outside the scope of this paper (but see Scott et al. 2001 for a relevant analysis of their distribution and influence).

We used Omernik's (1987) ecoregion framework to summarize the data because it was developed by synthesizing information on climate, geology, physiography, soils, vegetation, hydrology, and human factors and it reflects patterns of land-cover and land-use potential that should correlate strongly with patterns observed in the data. The ecoregion classification is hierarchically nested, such that ecoregions at the coarsest scale (Level I) are made of many smaller ecoregions (Levels II and III) and, by definition, contain more heterogeneity. For the national-level data presented here, we use Level I ecoregions (Fig. 1). For the more detailed investigation in the East, we use Level III ecoregions. All counties were assigned to only one ecoregion type, based on the ecoregion in which the centroid of the county falls.

\footnotetext{
${ }^{6}\langle$ http://www-atlas.usgs.gov/ $\rangle$
}

To account for urban-rural differences, we use a classification of counties as metropolitan and nonmetropolitan. The metropolitan and nonmetropolitan designations were made by the U.S. Office of Management and Budget in 1993. In order to recognize the dynamic nature of these designations, we subdivided metropolitan counties into those that persisted as metropolitan from 1960-1993, and those that transitioned from nonmetropolitan to metropolitan during the same period. Because 1960 was the first year for which the modern metropolitan county designations were available, we were unable to identify counties that transitioned from nonmetropolitan to metropolitan between 1950 and 1960 , resulting in the misclassification of a few counties. However, we expect this slight misclassification to have little effect on our results. Because metropolitan areas have significant spillover effects into adjacent nonmetropolitan areas, for example because of commuting, we further subdivided nonmetropolitan counties into those that were adjacent to a metropolitan area, i.e., they share a border with a metropolitan county, and those that were nonadjacent.

\section{Population data}

The population data for this paper were extracted from the 1950, 1970, and 2000 U.S. Censuses of Population (Forstall 1996, U.S. Bureau of the Census 2001). Total population counts in each county were divided by the private land areas to yield estimates of population density in each of the three years.

\section{Urbanization data}

To characterize urbanization, we used data derived from the 1990 and 2000 U.S. censuses to describe housing density at the block-group level in each of those years (Theobald 2001). Housing units are typically single-family homes, but can also be townhomes, apartments, and condominiums. Reported data on the numbers of housing units of various ages, in 10-yr increments, were used to compute the numbers of housing units in each decade prior to 1990. To account for possible underestimation of historical units, we adjusted the historical estimates using established methods to ensure that the total number of units across all block groups within a county equaled the number recorded in each decadal census (Radeloff et al. 2001, Theobald 2001)

Housing density is the number of units per acre, quantified at the level of block groups, of which there are nearly one-quarter million in the United States. We define three levels of housing density: urban, greater than 1 unit per 1 acre; exurban, between 1 unit per 1 acre and 40 acres ( 0.4 ha and 16.2 ha); and rural, less than 1 unit per 40 acres (16.2 ha). We then aggregated the 2000 block groups (for the 2000 data) and 1990 block groups (for all other decades) into counties and com- 
puted the proportion of the area in the county in block groups with the three different levels of density.

Urbanization can also be measured in more direct ways but not for the entire country over the entire period we are investigating. For example, according to the Natural Resources Inventory (NRI), developed land occupies a small portion of the overall landscaperoughly 6.6\% in 1997 (NRCS 2000) -but has been increasing rapidly. From 1982 to 1997 , over 25 million acres of land have been developed, totaling over 98.2 million acres in 1997. Developed land is composed of high-density urban areas (small built-up areas; 6.1 million), low-density urban (70.3 million), and rural transportation land (98.2 million).

\section{Agriculture data}

Agricultural land-use change was characterized using a data set compiled by Waisanen and Bliss (2002) and that includes data collected from 1850 to 1947 by the U.S. Census and thereafter by the U.S. Department of Agriculture. Because the Census of Agriculture was not taken during the same years as the Census of Population and Housing, we used the dates closest to our target dates of 1950,1970, and 2000. The source for data in 1949 and 1974 was the Economic Research Service (Economic Research Service 1999) and, in 1997, the National Agricultural Statistics Service (U.S. Department of Agriculture 1997). The total amount of cropland includes harvested cropland, cropland used only for pasture or grazing, cropland on which all crops failed, cropland in cover crops, cropland in cultivated summer fallow, idle cropland, and land under conservation reserve or wetland reserve programs (Waisanen and Bliss 2002). We computed the percentage of land in cropland by dividing the total cropland by the private land area.

\section{Detailed land-cover change}

The U.S. Geological Survey (USGS) has undertaken an investigation of the rates, causes, and consequences of land-cover change between 1973 and 2000 within the 84 Level III ecoregions defined by Omernik (1987) for the conterminous United States (Loveland et al. 2002). Results are presented on land-cover change in the southeastern United States. The fundamental approach was to estimate change in each ecoregion using a probability sample of $20 \times 20 \mathrm{~km}$ or $10 \times 10 \mathrm{~km}$ blocks randomly selected within the ecoregions (Loveland et al. 2002). For each block, five dates of Landsat imagery (nominally 1973, 1980, 1986, 1992, and 2000) were selected, and land cover was manually interpreted from the imagery. The sample-block interpretations were compared to determine changes between periods, and the change statistics were extrapolated to produce change estimates for the entire ecoregion. The goal was to detect $\pm 1 \%$ of the total change at an $85 \%$ confidence level.
RESUlts

\section{Demographic trends}

Overall population change between 1950 and 2000.-Population gains in the last 50 years were smallest in the Northern Forests, Eastern Temperate Forests, and Great Plains. Each of these regions grew at a rate near or below that for the nation as a whole (Fig. 2a). In contrast, regions in the West grew at rates well above the national average. The proportion of the total population residing in the Eastern Temperate Forests and Great Plains dropped from $84 \%$ in 1950 to $76 \%$ in 2000 . This disparity was not the result of population losses in the two dominant regions but occurred because they grew at a slower rate than other areas of the country. In the Eastern Temperate Forests, much of the population growth occurred in the Southeast especially in the uplands and coastal zones of the region (Fig. 2a).

The map also reveals that, despite the rural turnaround of the 1970s and the rebound of the 1990s, the agricultural heartland of the country including the Great Plains experienced widespread population losses during the period. Other pockets of loss included the Mississippi Delta and the Appalachians.

In 1950 , about $72 \%$ of the population resided in areas that were metropolitan or would become so. By 2000, these same areas contained $81 \%$ of the population. Much of the metropolitan gain during the period occurred in areas that shifted from nonmetropolitan to metropolitan status between 1960 and 1993 (Nucci and Long 1996). However, the fact remains that, by 2000, a larger share of the population resided within metropolitan counties. Though continuously nonmetropolitan areas contained 11.6 million $(27.3 \%)$ more people in 2000 than they did in 1950, metropolitan areas gained 114.2 million (106\%). Though transitional counties grew more rapidly than continuously metropolitan counties ( $165 \%$ vs. $95 \%$, respectively), threequarters of the total gain in metropolitan population was in the continuously metropolitan counties (Appendix).

Population change 1950-1970 vs. 1970-2000.-Between 1950 and 1970, the nonmetropolitan areas of the country grew slowly $(2 \%)$, whereas the population in transitional and continuous metropolitan counties increased by nearly 50 million (45\%) (Appendix). Between 1970 and 2000, though the largest population gains still accrued to metropolitan areas, the difference between the metropolitan (42\%) and nonmetropolitan (25\%) growth rates was much narrower.

Growth between 1950 and 1970 was most rapid in transitional counties in the Eastern Temperate Forests and in continuously metropolitan counties in the Great Plains. In these two ecoregions, which contained the bulk of the U.S. population (84\%) in 1950, the nonadjacent counties experienced population losses of 


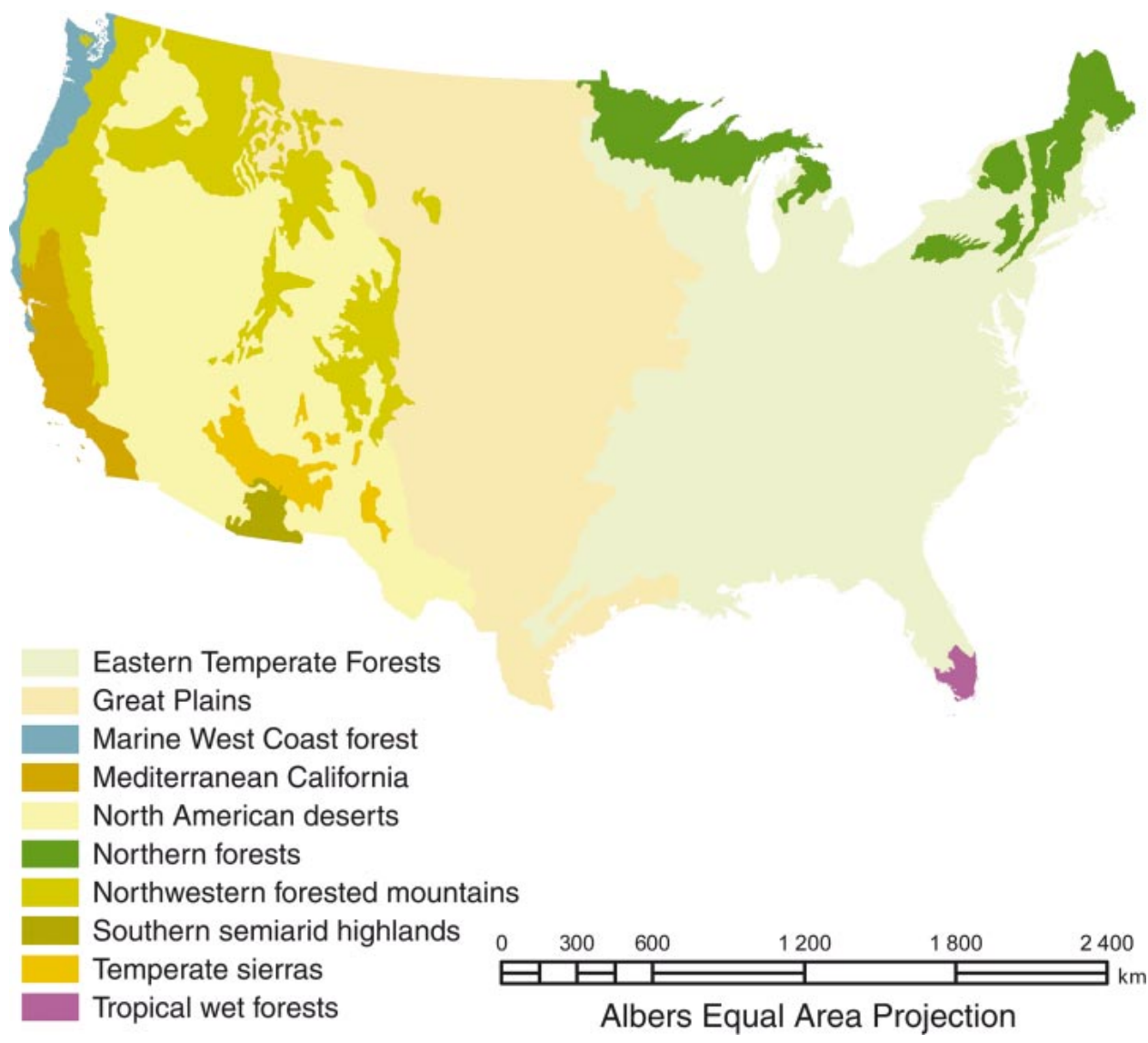

FIG. 1. Extent of Level I ecoregions in the conterminous United States, based on Omernik (1987).

$5.8 \%$ and $6.5 \%$, respectively, in the same period. On the Great Plains, the adjacent counties lost population during this time and the only counties that gained population from 1950 to 1970 were the metropolitan counties. Between 1970 and 2000, however, in the Eastern Temperate Forests, nonadjacent counties gained population more rapidly (i.e., 23\%) than did the continuously metropolitan areas (i.e., 17\%). Growth during this period was most rapid in transitional metropolitan counties in both the Eastern Temperate Forest and the Great Plains. In the Eastern Temperate Forest, the gains in nonmetropolitan areas in the later period were more than sufficient to offset earlier population losses. As a result, each county type in the Eastern Temperate Forests ended the century with more people than they had in 1950. In the Great Plains, the adjacent and nonadjacent nonmetropolitan counties also gained, though the latter group grew only slightly. These gains were not sufficient to offset earlier losses leaving non-adjacent counties on the Great Plains as the only group with fewer people in 2000 than they had in 1950.

Most other regions had proportionately larger gains from 1950 to 1970 than those in the Great Plains and Eastern Temperate Forests, but the same overall pattern of growth occurred. Continuously metropolitan counties tended to grow fastest during this period. Even the nonadjacent counties had overall population gains in most other regions, although there were several regions including the Northern Forests and the Northwest Forested Mountains where many nonadjacent counties lost population. Population gains were greatest in Mediterranean California, which included fast growing Los Angeles, San Diego, and San Francisco. The Interior Basins and Deserts of the west also experienced large population gains, as did the Tropical Wet Forests ecoregion centered on Miami. Population gains were extremely widespread from 1970 to 2000 . They ranged from modest in the Northern Forests to substantial in several of the Western ecoregions. Gains were generally largest in transitional metropolitan areas, and in several regions gains in adjacent counties exceeded those in continuously metropolitan areas.

\section{Urbanization trends}

In 1950, the conterminous United States had less than $1 \%$ of land at urban densities $\left(19296 \mathrm{~km}^{2}\right)$ and about $5 \%$ at exurban densities $\left(270608 \mathrm{~km}^{2}\right)$; by 2000 , these densities had grown to nearly $2 \%\left(93538 \mathrm{~km}^{2}\right)$ 
and 25\% (1.39 million $\mathrm{km}^{2}$ ), respectively (Appendix). Urban and exurban settlement occurred rapidly, and together they cover four to five times the area they did in 1950. Though urban densities were generally rare outside metropolitan counties (and we, therefore, do not explore the patterns in detail), exurbanization has occurred disproportionately outside of existing metropolitan counties. Exurbanized area grew nearly sevenfold from 1950 to 2000 in transitional metropolitan counties, and nearly tenfold in counties adjacent to metropolitan counties.

The most dramatic increases in exurbanized area occurred throughout the Eastern Temperate Forest and in several Western ecoregions (Fig. 2b). Exurbanized area increased eightfold in both the adjacent and nonadjacent nonmetropolitan counties of the Eastern Temperate Forest and nearly sevenfold in the transitional metropolitan counties (Appendix). Except for the Deep South and extreme western edges of the region, increases were consistently high across the region.

The Great Plains experienced increases in exurban area as well, but the most dramatic increases were in the transitional metropolitan counties (nearly tenfold vs. about threefold in nonmetropolitan counties). Though populations declined in nonadjacent nonmetropolitan counties on the Plains (especially between 1950 and 1970), exurbanized area increased.

Exurban growth in the conterminous United States as a whole was more rapid during the period 19501970 than from 1970-2000, with increases $170 \%$ and $90 \%$, respectively. This general pattern was true for most ecoregions, including the Eastern Temperate Forest and the Great Plains. Two ecoregions stand out from this general trend. The Northern Forests and Northwestern Forested Mountains both experienced more rapid growth in the exurbanized area between 1970 and 2000 than they did between 1950 and 1970 .

\section{Agriculture trends}

Throughout the United States as a whole, cropland area decreased $11 \%$ between 1950 and 2000, from 35\% of land area to $31 \%$ (Appendix). Decreases in cropland area were most consistent throughout the two large Eastern ecoregions, Eastern Temperate Forest, and Northern Forests. Cropland area dropped by one-fifth in the Eastern Temperate Forest and by nearly one-half in the Northern Forests between 1950 and 2000 (Appendix), a total decline of approximately $19000 \mathrm{~km}^{2}$. Though declines were most rapid in continuously metropolitan counties $(35 \%)$, followed by transitional counties $(25 \%), 53 \%$ of the total decline in cropland area in the East (i.e., $100000 \mathrm{~km}^{2}$ ), occurred in nonmetropolitan counties compared with $47 \%$ (i.e., 90000 $\mathrm{km}^{2}$ ) in metropolitan counties. The exceptions to the broad pattern of cropland decline in the East were areas of the Corn Belt, i.e., from Iowa to Ohio, the Mississippi Delta region, and South Florida (Fig. 2c).
The Great Plains, though they experienced substantial declines in population, experienced very little change in the area in crops, declining by less than $1 \%$ overall (Appendix). In fact, though both continuous and transitional metropolitan counties experienced declines in the cropland between 1950 and 2000 in the Great Plains, primarily due to conversion to urban uses, cropland area increased slightly in nonmetropolitan counties.

\section{Level III southeastern ecoregions}

Land-cover change analysis in seven Eastern U.S. Level III ecoregions revealed a range of land-use and land-cover change patterns (Fig. 3). The per-period rates of spatial change, i.e., the amount of land that has changed from one land-cover type to another (Table 1), reveal two main trends. First, there were significant differences in the rates of change between ecoregions. While the Plains ecoregions (Southeastern Plains and Middle Atlantic Coastal Plains) showed very high rates of change per period, the Appalachian (North Central Appalachia and Blue Ridge) exhibited lower rates of change. Second, the rates of change were generally increasing from the beginning of the study period for most of the ecoregions. The highest rates of change occurred in the last period (1992-2000).

The overall spatial rates of change highlight the amount of land modified over the 27 -yr period (Table 1). Ecoregions with low overall rates of change (i.e., Northern Piedmont, Atlantic Coast Pine Barrens, and Blue Ridge) were experiencing unidirectional land transformations (i.e., urbanization). Ecoregions with high rates of change (i.e., Southeastern Plains, Middle Atlantic Coastal Plains) are generally experiencing changes in rural land uses (i.e., forest harvesting, forest replanting, agriculture).

The highest rates of urban change occurred in the two ecoregions comprising the eastern seaboard megalopolis: (1) Atlantic Coast Pine Barrens (New York City, Trenton) and (2) Northern Piedmont (Newark, Philadelphia, Baltimore, and Washington, D.C.) (Table 2 ). The fast-growing Piedmont ecoregion was also experiencing significant levels of urbanization. The Piedmont increase was almost $4.5 \%$, or $7368 \mathrm{~km}^{2}$ of new urban land in the ecoregion since 1973. This was $44 \%$ of the urbanization that occurred in the seven eastern ecoregions $\left(16739 \mathrm{~km}^{2}\right.$ increase in the seven ecoregions). Nearly $75 \%$ of new urban lands in the Piedmont were transformed from forests with most of the rest resulting from the conversion of agricultural land. This pattern is in sharp contrast to the adjacent Northern Piedmont where $65 \%$ of the conversion was from valley farmlands. The Middle Atlantic Coastal Plains experienced modest increases in urban land-approximately $2.5 \%$ (or $1986 \mathrm{~km}^{2}$ ) with a significant percentage of this change associated with coastal recreation. 

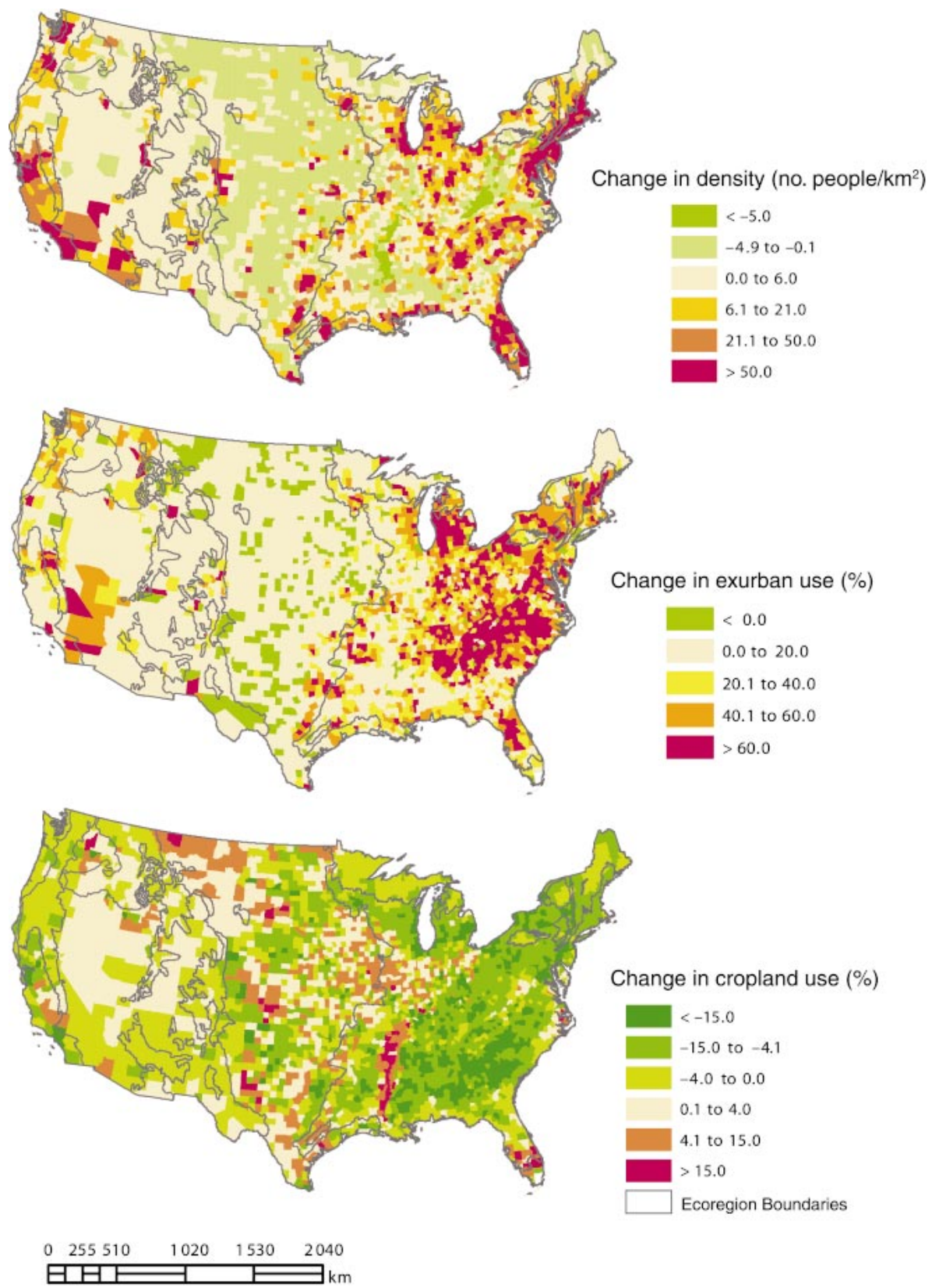

FIG. 2. Maps of change by county in (a) population density, (b) percentage of area exurbanized, and (c) percentage of land in agriculture, between 1950 and 2000.

All seven eastern ecoregions experienced a loss of agricultural land. In the Northern Piedmont, Atlantic Coast Pine Barrens, and Piedmont, most of the loss was attributable to urbanization (Table 2). The Southeastern Plains lost agricultural land to industrial forest land uses. The overall loss of agricultural land in the seven ecoregions was $13740 \mathrm{~km}^{2}$.

Overall, $15407 \mathrm{~km}^{2}$ of forest cover were lost in the seven ecoregions since 1973. The Piedmont and Middle Atlantic Coastal Plain lost the most forest cover (Table
2). Forest change in most of the seven ecoregions was generally cyclic, with forest planting, growth, and harvesting stages. The land cover would be either forest or mechanically disturbed (clear cutting), depending on stage. The highest levels of harvesting activity, indicated by mechanical disturbance to land, correspond to the range of Loblolly Pine (Pinus taeda) including the Southeastern Plains, Middle Atlantic Coastal Plain, and Piedmont (Table 2). When combining forest cover and mechanized disturbed lands into a forest land-use cat- 
egory, six of the seven ecoregions still had declining levels of forestland (Table 2). The Southeastern Plains was the only ecoregion with increased forest land use.

\section{DisCUSSION}

Since at least the time that Leopold (1948) described his "land ethic," ecologists have recognized the importance of how individuals use the land in determining the structure and function of ecological systems. Because the dynamics of land use have such serious implications (see Dale et al. 2000 and the other papers in this Invited Feature for reviews), understanding these dynamics can help ecologists better contribute to policy debates about land management. Furthermore, understanding the drivers of these dynamics is necessary for informed estimates about the likely future of these trends and the effectiveness of various approaches to managing them. In particular, the data presented here focus on the dramatic changes that have occurred on private lands within the conterminous United States. Clearly, private landowners are responding to stimuli other than ecological principles in deciding how to use their land. Yet, their decisions have serious ecological consequences.

Demographic trends in the United States during the past 50 years can be characterized in two distinctly different eras. The first, lasting from 1950 through 1970, was an era of metropolitan growth. Population in nonmetropolitan areas grew little, if at all; what growth there was occurred when births were sufficient to offset deaths and out migration. Throughout this era, the vast majority of nonmetropolitan counties lost migrants to the nation's urban centers. Rural people were attracted by the economic and social opportunities in urban areas and pushed out of rural areas by mechanization and the replacement of labor with capital in agriculture and other extractive industries. Most of those people migrating out of rural areas were young adults (Fuguitt and Heaton 1995, Johnson and Fuguitt 2000). Within metropolitan areas, there was significant population deconcentration from the older urban cores to the rapidly expanding suburbs.

This pattern changed abruptly in the 1970s with the occurrence of the "rural population turnaround." For the first time in at least 150 years, rural population gains during the 1970s exceeded those in metropolitan areas (Beale 1975, Beale and Fuguitt 1975, Vining and Strauss 1977). Even more surprising was the reversal of the net flow of migrants, so that it was from metropolitan to nonmetropolitan counties. The shift was fueled, in part, by the deconcentration of the urban population and also by the rising importance to migration decision making of noneconomic factors (e.g., natural amenities and recreational opportunities) (Wardwell 1982, Fuguitt 1985). The turnaround waned in the 1980s as demographic trends shifted back to traditional patterns of slower rural than urban growth and a net migration gain to metropolitan areas. However, since 1990, there has been a rural rebound with widespread population and migration gains in nonmetropolitan counties (Johnson and Beale 1994, Johnson 1999). The overall population trend between 1970 and 2000 appears to be one of selective deconcentration in both the metropolitan and nonmetropolitan areas of the country (Long and Nucci 1997, Frey and Johnson 1998). This trend appears to have parallels in other developed countries (Boyle and Halfacree 1998).

Though urbanization in metropolitan areas represents the expansion of the developed area within a metropolitan framework, expansion in nonmetropolitan counties likely reflects the results of the population turnaround and rural rebound described above, as well as the effects of decreasing household sizes and settlement densities (Liu et al. 2003). The increase in exurbanized area on the Plains (especially between 1950 and 1970), concurrent with population declines in nonadjacent nonmetropolitan counties, highlights the importance of decreased household size and settlement densities. Because this exurban development was so rapid in nonmetropolitan counties, it affects a much larger area than do densely settled cities and "urban sprawl," which suggests contagious growth out from a city center, may be an inadequate name for it. We suggest that the pattern represents a "rural sprawl," indicating a pattern of development decreasingly linked by proximity to urban centers and increasingly driven by access to open space and recreational opportunities.

The more rapid growth in the exurbanized area of Northern Forests and Northwestern Forested Mountains between 1970 and 2000 compared with 1950 and 1970 , which stands in contrast to all other regions, exemplifies the increasing importance of amenity-driven development that has been evident since 1970. With their forested landscapes, beautiful mountains (in the West and East), and plentiful inland lakes (in the North), coupled with the increasing importance of noneconomic factors in the location decisions made by many Americans, these regions began developing at more rapid rates than in the past. Though population gains were modest in these areas, the increase in exurbanized area was relatively dramatic. These highamenity areas are often rich in biodiversity, and their attraction to in-migrants and for second homes has serious ecological consequences (Hansen et al. 2002, Schnaiberg et al. 2002).

While declines in cropland area can be partially attributed to increases in productivity in the agricultural sector and intensification in areas that remain in agriculture, decreases were most dramatic in Metropolitan counties - cropland dropped by one-quarter in Metropolitan areas vs. one-tenth in nonmetropolitan areassuggesting that some of the decline can be attributed to appropriation of agricultural land for development. The greater total amount of cropland loss in nonmet- 


\section{3-2000 Land Cover Trends}

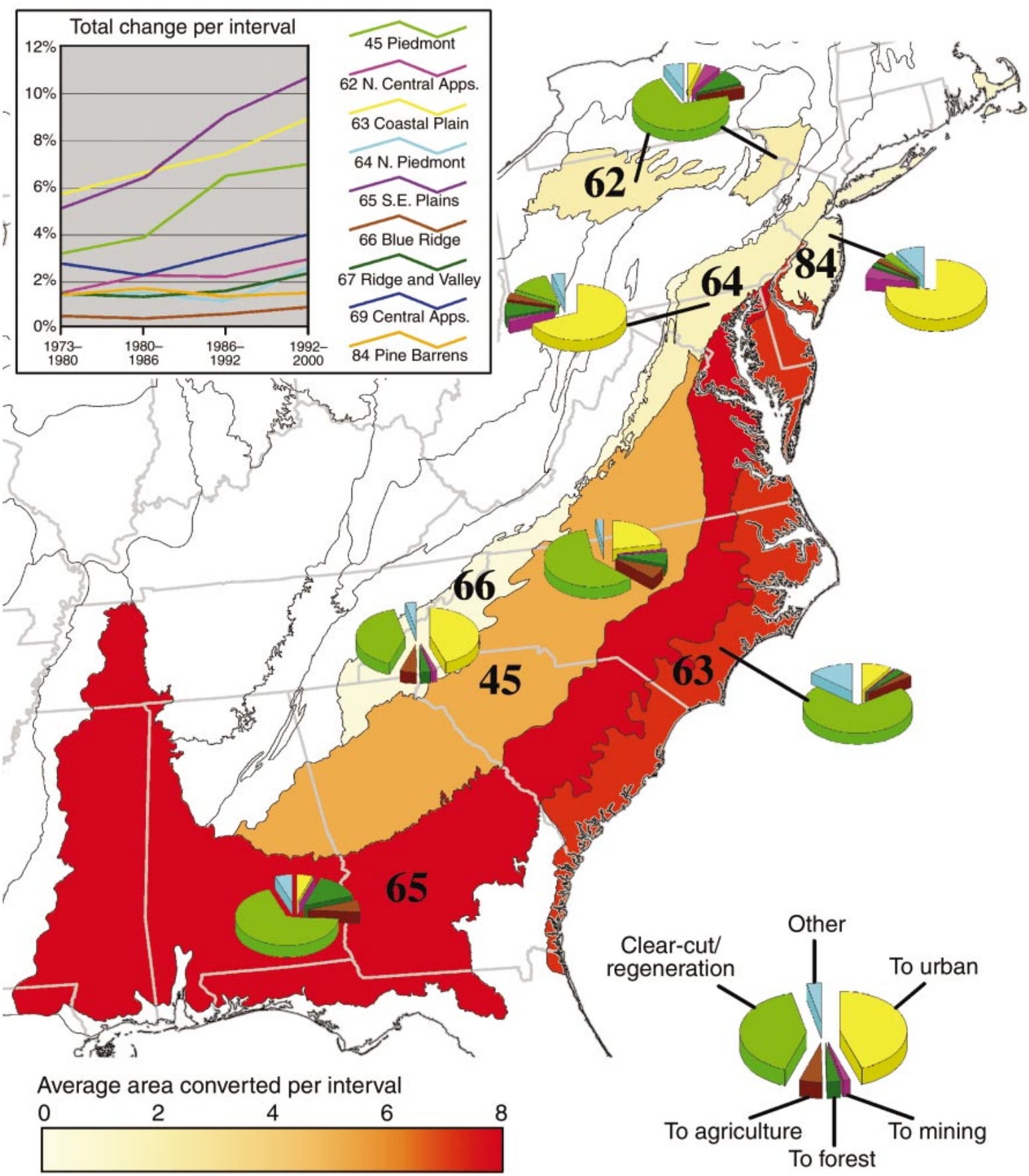

FIG. 3. Summary of changes taking place in seven eastern ecoregions. In this figure, ecoregion color represents overall change rates, and the pie charts describe the major types of transformations taking place (i.e., in ecoregion 84, Atlantic Coastal Pine Barrens, $75 \%$ of the change is to urban land cover). The inset graph illustrates overall change for each analysis period and provides a key to the ecoregion codes.

ropolitan counties, along with the more dramatic declines in the Northern Forests, suggests that not all the decline can be explained simply by conversion to urban development. The Northern Forest, especially, is an area with both poor soil and a difficult climate for cropland agriculture. While some of the cropland in the Northern Forests was converted to exurban development, much also transitioned to more natural vege- 
TABLE 1. Rates of change (\%) for each temporal interval in seven eastern ecoregions, USA.

\begin{tabular}{lccrrr}
\hline \hline \multicolumn{1}{c}{ Ecoregion } & 1973-1980 & 1980-1986 & 1986-1992 & 1992-2000 & Overall \\
\hline Southeastern Plains & 5.1 & 6.4 & 9.1 & 10.7 & 22.9 \\
Middle Atlantic Coastal Plains & 5.7 & 6.6 & 7.4 & 8.9 & 19.1 \\
Piedmont & 3.0 & 3.9 & 6.8 & 6.8 & 14.5 \\
North Central Appalachia & 1.5 & 2.3 & 2.2 & 2.9 & 5.6 \\
Northern Piedmont & 1.4 & 1.5 & 1.3 & 2.6 & 5.6 \\
Atlantic Coast Pine Barrens & 1.5 & 1.7 & 1.4 & 1.5 & 4.2 \\
Blue Ridge & 0.5 & 0.4 & 0.6 & 0.9 & 2.0 \\
\hline
\end{tabular}

tation covers (Brown et al. 2000). Agricultural abandonment in this and other areas may present important opportunities for restoration of natural and, perhaps, native habitats.

The pattern of agricultural stability on the Great Plains may be surprising, at first, when compared with the population and urbanization data. This result, however, suggests that, on the Great Plains, the primary driver of declining agricultural land is urban expansion but that this decline is nearly completely made up by cultivation of land elsewhere. Also, the population declines in the Great Plains are not explained by a wholesale decline in agricultural activity, merely by its conversion from a labor- to a capital-intensive activity. The Great Plains, and other areas in the Western United States, experienced pockets of agricultural expansion in the post-1950s era due to the development of irrigated agriculture. Public policy via the Reclamation Act and improvements in irrigation technology combined to motivate bringing significant areas into irri- gation along the Columbia River, Snake River, and the high plains of western Kansas. Intensification of agriculture in selected regions throughout the United States raises concerns about the ecological consequences of increased use of irrigation, chemical fertilizers, herbicides, and pesticides, though these trends are outside the scope of this paper.

The analysis of land-cover changes in the Southeastern ecoregions provides a finer-grained picture of the landscape changes that were occurring and of their causes. In the Atlantic Coast Pine Barrens and the Northern Piedmont, urban growth is resulting from the extension of transportation systems and along the emerging beltway cities (Erickson and Gentry 1985, Browning 1990). The Piedmont is an area associated with rapid growth and is one of three of the fasted growing regions in the country (Fonseca and Wong 2000). High population density, a ready labor force, and the well-connected transportation corridors are making the area one of the new sunbelt growth areas.

TABLE 2. Land-cover and land-use percentages and rates of change (\%) in seven eastern ecoregions.

\begin{tabular}{|c|c|c|c|c|c|c|c|c|}
\hline Class & Year & $\begin{array}{c}\text { Middle } \\
\text { Atlantic } \\
\text { Coastal Plain }\end{array}$ & $\begin{array}{l}\text { Atlantic } \\
\text { Coast Pine } \\
\text { Barrens }\end{array}$ & $\begin{array}{l}\text { South- } \\
\text { eastern } \\
\text { Plains }\end{array}$ & $\begin{array}{l}\text { Northern } \\
\text { Piedmont }\end{array}$ & Piedmont & Blue Ridge & $\begin{array}{c}\text { North } \\
\text { Central } \\
\text { Appalachia }\end{array}$ \\
\hline Urban & $\begin{array}{l}1973 \\
1980 \\
1986 \\
1992 \\
2000\end{array}$ & $\begin{array}{l}6.3 \\
6.9 \\
7.5 \\
8.2 \\
8.8\end{array}$ & $\begin{array}{l}24.4 \\
25.4 \\
26.7 \\
27.7 \\
29.0\end{array}$ & $\begin{array}{r}9.0 \\
9.2 \\
9.5 \\
9.8 \\
10.4\end{array}$ & $\begin{array}{l}22.7 \\
23.6 \\
24.5 \\
25.2 \\
27.3\end{array}$ & $\begin{array}{l}11.9 \\
12.7 \\
13.2 \\
14.5 \\
16.4\end{array}$ & $\begin{array}{l}6.1 \\
6.3 \\
6.5 \\
6.7 \\
7.2\end{array}$ & $\begin{array}{l}1.3 \\
1.4 \\
1.5 \\
1.6 \\
1.7\end{array}$ \\
\hline Agriculture & $\begin{array}{l}1973 \\
1980 \\
1986 \\
1992 \\
2000\end{array}$ & $\begin{array}{l}22.2 \\
22.4 \\
22.4 \\
22.3 \\
22.2\end{array}$ & $\begin{array}{l}16.8 \\
16.4 \\
15.6 \\
14.9 \\
14.0\end{array}$ & $\begin{array}{l}24.5 \\
24.8 \\
24.5 \\
22.6 \\
21.5\end{array}$ & $\begin{array}{l}37.7 \\
36.9 \\
36.1 \\
35.5 \\
34.4\end{array}$ & $\begin{array}{l}24.4 \\
24.2 \\
23.9 \\
23.3 \\
23.1\end{array}$ & $\begin{array}{l}13.7 \\
13.7 \\
13.7 \\
13.6 \\
13.7\end{array}$ & $\begin{array}{l}7.4 \\
7.4 \\
7.2 \\
7.1 \\
7.1\end{array}$ \\
\hline Forest cover & $\begin{array}{l}1973 \\
1980 \\
1986 \\
1992 \\
2000\end{array}$ & $\begin{array}{l}34.7 \\
33.2 \\
32.5 \\
31.2 \\
31.4\end{array}$ & $\begin{array}{l}22.7 \\
22.1 \\
21.5 \\
21.2 \\
20.9\end{array}$ & $\begin{array}{l}53.3 \\
52.4 \\
51.9 \\
52.6 \\
52.3\end{array}$ & $\begin{array}{l}36.9 \\
36.7 \\
36.5 \\
36.3 \\
35.4\end{array}$ & $\begin{array}{l}59.8 \\
59.0 \\
57.9 \\
56.4 \\
55.1\end{array}$ & $\begin{array}{l}79.5 \\
79.1 \\
79.0 \\
78.6 \\
78.3\end{array}$ & $\begin{array}{l}87.4 \\
87.2 \\
87.3 \\
86.8 \\
86.6\end{array}$ \\
\hline Mechanize disturbed & $\begin{array}{l}1973 \\
1980 \\
1986 \\
1992 \\
2000\end{array}$ & $\begin{array}{l}2.3 \\
3.0 \\
3.3 \\
4.0 \\
4.1\end{array}$ & $\begin{array}{l}0.2 \\
0.0 \\
0.1 \\
0.1 \\
0.1\end{array}$ & $\begin{array}{l}2.2 \\
2.4 \\
2.9 \\
3.8 \\
4.8\end{array}$ & $\begin{array}{l}0.1 \\
0.2 \\
0.2 \\
0.2 \\
0.2\end{array}$ & $\begin{array}{l}0.9 \\
1.1 \\
1.9 \\
2.5 \\
2.0\end{array}$ & $\begin{array}{l}0.0 \\
0.2 \\
0.1 \\
0.2 \\
0.2\end{array}$ & $\begin{array}{l}1.0 \\
1.2 \\
0.8 \\
1.4 \\
1.5\end{array}$ \\
\hline Forest use & $\begin{array}{l}1973 \\
1980 \\
1986 \\
1992 \\
2000\end{array}$ & $\begin{array}{l}37.0 \\
36.2 \\
35.8 \\
35.2 \\
35.5\end{array}$ & $\begin{array}{l}22.9 \\
22.2 \\
21.6 \\
21.3 \\
20.9\end{array}$ & $\begin{array}{l}55.5 \\
54.8 \\
54.7 \\
56.4 \\
57.1\end{array}$ & $\begin{array}{l}37.0 \\
36.9 \\
36.7 \\
36.5 \\
35.6\end{array}$ & $\begin{array}{l}60.7 \\
60.1 \\
59.8 \\
58.9 \\
57.1\end{array}$ & $\begin{array}{l}79.6 \\
79.3 \\
79.1 \\
78.9 \\
78.5\end{array}$ & $\begin{array}{l}88.4 \\
88.4 \\
88.1 \\
88.2 \\
88.0\end{array}$ \\
\hline
\end{tabular}


The lower level of growth observed on the Middle Atlantic Coastal Plains reflects the importance of the ecoregion's diverse agricultural economy and growing emphasis on forest industry (Bascom and Gordon 1997).

One limitation of the satellite- and sampling-based approach to estimating land-cover change is that it, like the county-level agricultural census data, cannot detect some significant land-use and land-management trends. For example, while agricultural lands were lost in the Southeast, there was an intensification of agricultural land use due to increases in confinement feeding operations. Poultry confinement units have been found in all ecoregions (Hart 1980) and hog confinement units have been increasingly used in the Middle Atlantic Coastal Plains (Hart 1996).

Through intensive silviculture, short rotations of $20-$ 25 years can produce mature, harvestable trees (Gresham 2002). In contrast, the forest management practices of the Appalachian ecoregions reflect a multiple-use strategy, reducing both the amount and size of clear cut forest parcels. With a gain of $5626 \mathrm{~km}^{2}$ of forest land use, the Southeastern Plains has been transitioning to a major industrial forestry region. With the longstanding history of farmland abandonment due to the challenges of farming the drought-prone, nutrient-poor soils, coupled with the ability to use short-rotation silviculture practices, the consolidation of the abandoned lands into wood products and land management company holdings may hasten the transition of this ecoregion.

\section{CONCLUSiOnS}

We have synthesized data about the patterns and trends of developed and agricultural land use across the entire conterminous United States from 1950 to 2000 and interpreted how these patterns relate to ecoregions and to the likely factors that drive them. This study is intended to raise awareness of these trends and to provide ecologists with the best available data at the national level. Space limitations preclude sufficient treatment of the ecological implications of these changes, these are therefore left for others. Further, we have not dealt with other land management and cover changes, including changes in forest or agricultural management practices, like inputs of chemical fertilizers, pesticides, and herbicides, which have important ecological consequences.

The demographic data suggest several general conclusions. First, population growth was widespread between 1950 and 2000. The one notable exception was in the Great Plains. Second, the population has shifted from east to west. Third, the population residing in the vast agricultural region encompassed by the Great Plains has remained about the same size as it was in 1950 but has become more concentrated in metropolitan areas. Finally, a larger proportion of the American population resides in the nation's metropolitan areas in 2000 than was the case in 1950 .

To date, understanding the role of urbanization in the loss of both natural habitat and of agricultural land has been impeded by a lack of data that differentiate land-use changes at and beyond the urban fringe (Theobald 2001). Separating growth into density classes at a relatively fine-grain (within county) allows the landuse change trajectory (i.e., urbanization vs. naturalamenities-based change) to be better distinguished, aiding our understanding of the differences and similarities of these patterns. Settlement at exurban densities increased in area five- to sevenfold between 1950 and 2000 , with significant gains in nonmetropolitan counties. This dispersed pattern of development is likely to have significant effects on both ecological processes and management over large areas in the U.S.

Cropland area declined in two large Eastern ecoregions, due partially to conversion of cropland to urban development and partially to abandonment of marginally productive lands (especially in the North and Deep South). Abandonment of marginally productive lands may present opportunities for ecological restoration within the Eastern Temperate and Northern Forest regions. Cropland area in the Great Plains was relatively unchanged, but the same area was farmed by far fewer people than in 1950. This change illustrates the effects of mechanization and conversion from labor-intensive methods of farming to capital intensive approaches. It is important to note that these results only represent changes in the area of land cropped, and does not deal with effects of intensification on resource use and ecological impact associated with the remaining cropped areas, e.g., through more extensive irrigation or chemical fertilizer use.

Examination of land-cover changes within Level III ecoregions in the East and South revealed more about the processes by which land-cover conversion has proceeded. While some ecoregions have changed at similar rates (i.e., Northern Piedmont and North Central Appalachia), there are significant differences in the types of transformations taking place. Of the four cover types discussed, two (urban and mechanically disturbed) increased in area between 1973 and 2000. Urban lands increased by $16739 \mathrm{~km}^{2}$ while mechanical disturbances increased by $12595 \mathrm{~km}^{2}$. Both of these cover types result in loss of natural habitat and therefore have significant consequences that deserve further investigation. Forest and agricultural cover both decreased in area between 1973 and 2000, with forests losing 15407 $\mathrm{km}^{2}$ and agriculture losing $13740 \mathrm{~km}^{2}$.

Two issues emerge from our comparison of nationallevel and fine-level data sets. First, as with many ecological data, the scale and resolution of the data impose limits on the interpretation. Not only can trends in extent be resolved more precisely using finer-grained data, but land-use and land-cover types can be better 
differentiated and possible fragmentation effects can be measured. An important limitation of the nationallevel data presented in this paper is its lack of resolution below the county level. This causes us to miss changes that are occurring within counties. Many metropolitan counties, for example, have natural habitats that deserve special attention. Furthermore, counties vary in size, meaning that the available detail is much finer in the east than in the west, where counties are larger. Also, the very coarse grain of the ecological data (i.e., Level I ecoregions) simplified the analysis, but it forbids conclusions about all but the most general patterns. Second, although ecological studies have made use of land-cover data as surrogates for human activities, land use and other demographic data offer important additional, complementary information to strengthen insight into the human processes driving land-cover changes. Understanding these processes, together with the changes in land management, which are not presented here, is critical if one is to undertake efforts to affect policies to achieve particular ecological outcomes. Our approach has value, therefore, because it presents the best available data on changes in landuse areas with both national coverage and a long-term record. The data can provide context for more detailed investigations of land-use changes effects on ecological systems.

To better understand potential ecological effects of land-use change, more long-term, field-based, monitoring of land-cover and associated changes are needed across the urban to rural gradient (e.g., McDonnell et al. 1997). Remote sensing methodologies provide a means for better quantifying changes along the urban to rural gradient, but collection of land-use data through on-the-ground surveys are also needed. For example, in the past, NSF Long-Term Ecological Research sites were situated in very rural locations. More recently, two urban LTERs have been added (i.e., Phoenix and Baltimore; Grimm et al. 2000). These research efforts should be augmented with sites that lie between the urban and rural ends of the spectrum.

\section{ACKNOWLEDGMENTS}

Dr. Brown received support for his work from the NASA Land Cover Land Use Change Program (\# NAG5-11271), the National Wildlife Federation, and the USDA Forest Service, North Central Research Station. He acknowledges the research assistance provided by Vikalpa Jetly. Dr. Johnson's research was supported by a grant from the North Central Research Station of the USDA Forest Service. He acknowledges the research assistance provided by Tim Weddle of Loyola University-Chicago. Dr. Loveland's work was supported by grants from NASA and the U.S. Environmental Protection Agency, in addition to his own agency, the U.S. Geological Survey. Dr. Theobald's work was supported by grants from the William and Flora Hewlett Foundation, through the Center for the American West, the U.S. Environmental Protection Agency (STAR Grant \#R827449-01-0), and The Nature Conservancy's Smith Fellowship Program.

\section{Literature Cited}

Bascom, J., and R. Gordon. 1997. "Country living": rural non-farm population growth in the Coastal Plain Region of North Carolina. Pages 77-90 in Reshaping the countryside: perceptions and processes of rural change. CABI Publications, Wallinford, UK.

Beale, C. L. 1975. The revival of population growth in nonmetropolitan America. (ERS-605). Economic Research Service, U.S. Department of Agriculture, Washington, D.C., USA.

Beale, C. L., and G. V. Fuguitt. 1975. The new pattern of nonmetropolitan population change. Presented at the Conference on Social Demography, University of Wisconsin, Madison, Wisconsin, USA.

Boyle, P., and K. Halfacree. 1998. Migration in to rural areas. Wiley, Chichester, UK.

Brown, D. G., B. C. Pijanowski, and J.-D. Duh. 2000. Modeling the relationships between land-use and land-cover on private lands in the Upper Midwest, USA. Journal of Environmental Management 59:247-263.

Browning, C. E. 1990. The rise of the beltways: a powerful force for urban change. Focus on Geography 40(2):18-22.

Dale, V., S. Archer, M. Chang, and D. Ojima. 2005. Ecological impacts and mitigation strategies for rural land management. Ecological Applications 15:1879-1892.

Dale, V. H., S. Brown, R. A. Haeuber, N. T. Hobbs, N. Huntly, R. J. Naiman, W. E. Riebsame, M. G. Turner, and T. J. Valone. 2000. Ecological principles and guidelines for managing the use of land: a report from the Ecological Society of America. Ecological Applications 10:639-670.

Dobson, J. E., E. A. Bright, P. R. Coleman, R. C. Durfee, and B. A. Worley. 2000. A global population database for estimating population at risk. Photogrammetric Engineering \& Remote Sensing 66:849-858.

Economic Research Service. 1999. Historical census of agriculture data, 1949-1974. Records of the Economic Research Service (Record Group 354). Economic Research Service, U.S. Department of Agriculture, Washington, D.C., USA.

Erickson, R. A., and M. Gentry. 1985. Suburban nucleations. Geographical Review 75:19-31.

Fonseca, J. W., and D. W. Wong. 2000. Changing patterns of population density in the United States. Professional Geographer 52:504-517.

Forstall, R. L. 1996. Population of states and counties of the United States: 1790 to 1990. U.S. Bureau of the Census, Washington, D.C., USA.

Frey, W. H., and K. M. Johnson. 1998. Concentrated immigration, restructuring, and the selective deconcentration of the U.S. population. Pages 79-106 in P. J. Boyle and K. H. Halfacree, editors. Migration into rural areas: theories and issues. Wiley, London, UK.

Fuguitt, G. V. 1985. The nonmetropolitan turnaround. Annual Review of Sociology 11:259-280.

Fuguitt, G. V., and T. B. Heaton. 1995. The impact of migration on the nonmetropolitan population age structure, 1960-1990. Population Research and Policy Review 14:215-232.

Fulton, W., R. Pendall, M. Nguyen, and A. Harrison. 2001. Who sprawls most? How growth patterns differ across the U.S. Brookings Institution, Center on Urban and Metropolitan Policy, Washington, D.C., USA.

Gresham, C. A. 2002. Sustainability of intensive loblolly pine plantation management in the South Carolina Coastal Plain, USA. Forest Ecology and Management 155:69-80.

Grimm, N., J. M. Grove, S. T. A. Pickett, and C. L. Redman. 2000. Integrated approaches to long-term studies of urban ecological systems. Bioscience 50:571-584.

Hammer, R. B., S. I. Stewart, R. Winkler, V. C. Radeloff, and P. R. Voss. 2004. Characterizing spatial and temporal res- 
idential density patterns across the U.S. Midwest, 19401990. Landscape and Urban Planning 69:183-199.

Hansen, A. J., R. L. Knight, J. Marzluff, S. Powell, K. Brown, P. H. Gude, and K. Jones. 2005. Effects of exurban development on biodiversity: patterns, mechanisms, and research needs. Ecological Applications 15:1893-1905.

Hansen, A. J., R. Rasker, B. Maxwell, J. J. Rotella, J. Johnson, A. Wright Parmenter, U. Langner, W. Cohen, R. Lawrence, and M. V. Kraska. 2002. Ecological causes and consequences of demographic change in the New West. BioScience 52:151-168.

Hart, J. F. 1980. Land use change in a piedmont county. Annals of the Association of American Geographers 70(4):492-527.

Hart, J. F. 1996. Turmoil in tobaccoland. Geographical Review 86:550-572.

Huston, M. A. 2005. The three phases of land-use change: implications for biodiversity. Ecological Applications 15 $1864-1878$

Imhoff, M. L., W. T. Lawerence, D. Stutzer, and C. Elvidge. 1998. Assessing the impact of urban sprawl on soil resources in the United States using nighttime "city lights" satellite images and digital soils maps. Pages 13-22 in Perspectives on the land use history of North America: a context for understanding our changing environment. USGS/ BRD/BSR-1998-0003. U.S. Geological Survey, Washington, D.C., USA.

Johnson, K. M. 1999. The rural rebound. Population Reference Bureau Reports on America 1:1-20.

Johnson, K. M., and C. L. Beale. 1994. The recent revival of widespread population growth in nonmetropolitan areas of the United States. Rural Sociology 59:655-667.

Johnson, K. M., and G. V. Fuguitt. 2000. Continuity and change in rural migration patterns, 1950-1995. Rural Sociology 65:27-49.

Leopold, A. 1948. A Sand County almanac. Oxford University Press, New York, New York, USA.

Liu, J., G. C. Daily, P. R. Ehrlich, and G. W. Luck. 2003. Effects of household dynamics on resource consumption and biodiversity. Nature 421:530-533.

Long, L., and A. Nucci. 1997. The "clean break" revisited: is US population again deconcentrating? Environment and Planning A 29:1355-1366.

Loveland, T. R., T. L. Sohl, S. V. Stehman, A. L. Gallant, K. L. Sayler, and D. E. Napton. 2002. A strategy for estimating the rates of recent United States land-cover changes. Photogrammetric Engineering and Remote Sensing 68:1091-1099.

Lunetta, R. S., J. G. Lyon, B. Guindon, and C. D. Elvidge. 1998. North American landscape characterization datase development and data fusion issues. Photogrammetric Engineering and Remote Sensing 64:821-829.

Maizel, M., R. D. White, S. Gage, L. Osborne, R. Root, S. Stitt, and G. Muehlbach. 1998. Historical interrelationships between population settlement and farmland in the conterminous United States, 1790 to 1992. Pages 5-12 in Perspectives on the land use history of North America: a context for understanding our changing environment: USGS BRD/BSR-1998-0003. U.S. Geological Survey, Washington, D.C., USA.

McDonnell, M. J., S. T. A. Pickett, P. Groffman, and P. Bohlen. 1997. Ecosystem processes along an urban-rural gradient. Urban Ecosystems 1:21-36.

Natural Resources Conservation Service (NRCS). 2000. National Resources Inventory, 1997. U.S. Department of Commerce, Washington, D.C., USA.
Nucci, A., and L. Long. 1996. Spatial and demographic dynamics of metropolitan and nonmetropolitan territory in the United States. International Journal of Population Geography 1:165-181.

Omernik, J. M. 1987. Ecoregions of the conterminous United States. Annals of the Association of American Geographers 77:118-125.

Radeloff, V. C., A. Hagen, P. Voss, D. R. Field, and D. J. Mladenoff. 2000. Exploring the spatial relationship between census and land cover data. Society and Natural Resources 13:599-609.

Radeloff, V. C., R. B. Hammer, P. R. Voss, A. E. Hagen, D R. Field, and D. J. Mladenoff. 2001. Human demographic trends and landscape level forest management in the northwest Wisconsin Pine Barrens. Forest Science 47:229-241.

Ramankutty, N., and J. Foley. 1999. Estimating historical changes in land cover: North American croplands from 1850 to 1992. Global Ecology and Biogeography 8:381-396.

Schnaiberg, J., J. Riera, M. G. Turner, and P. R. Voss. 2002. Explaining human settlement patterns in a recreational lake district: Vilas County, Wisconsin, USA. Environmental Management 30:24-34.

Scott, J. M., F. W. Davis, R. G. McGhie, R. G. Wright, C. Groves, and J. Estes. 2001. Nature reserves: do they capture the full range of America's biological diversity? Ecological Applications 11:999-1007.

Theobald, D. M. 2001. Land-use dynamics beyond the American urban fringe. Geographical Review 91:544-564.

Turner, B. L., D. Skole, S. Sanderson, G. Fischer, L. Fresco, and R. Leemans. 1995. Land-use and land-cover change science/research plan. Joint publication of the International Geosphere-Biosphere Programme (Report No. 35) and the Human Dimensions of Global Environmental Change Programme (Report No. 7). Royal Swedish Academy of Sciences, Stockholm, Sweden.

U.S. Bureau of the Census. 2001. 2000 census of population and housing: summary file 1 United States. U.S. Bureau of the Census, Washington, D.C., USA.

U.S. Department of Agriculture. 1997. Census of agriculture, geographic area series, AC97-CD-Volume 1. U.S. Department of Agriculture, National Agricultural Statistics Service, Washington, D.C., USA.

Vesterby, M., and R. W. Heimlich. 1991. Land-use and demographic change: results from fast-growth counties. Land Economics 67:279-291.

Vesterby, M., and K. S. Krupa. 1997. Major uses of land in the United States, 1997. Statistical Bulletin No. 973. Economic Research Service, U.S. Department of Agriculture, Washington, D.C., USA.

Vining, D. R.,Jr., and A. Strauss. 1977. A demonstration that the current deconcentration of population in the United States is a clean break with the past. Environment and Planning A 9:751-758.

Vogelmann, J. E., T. Sohl, and S. M. Howard. 1998. Regional characterization of land cover using multiple sources of data. Photogrammetric Engineering and Remote Sensing 64:45-57.

Waisanen, P. J., and N. B. Bliss. 2002. Changes in population and agricultural land in conterminous United States counties, 1790 to 1997. Global Biogeochemical Cycles 16:1137.

Wardwell, J. M. 1982. The reversal of nonmetropolitan migration loss. Pages 23-33 in D. A. Dillman and D. J. Hobbs, editors. Rural society in the U.S. Westview Press, Boulder, Colorado, USA.

\section{APPENDIX}

A summary table of population density and private land areas occupied by urban, exurban, and crop land uses for each ecoregion and county type is available in ESA's Electronic Data Archive: Ecological Archives A015-056-A1. 